\title{
Effects of Nursing Recognition and Major Satisfaction of Nursing Students on Nursing Professionalism
}

\author{
Miok Kim ${ }^{1}$ \\ ${ }^{1}$ Professor, Nursing Department, TongMyung University, South Korea, citycoco@ hanmail.net
}

\begin{abstract}
The purpose of this study was to identify the effects of nursing recognition and major satisfaction of nursing students on nursing professionalism. The subjects of this study were 112 sophomore and junior nursing students in B city who were surveyed from March 25 to April 1, 2020. The collected data were analyzed using descriptive statistics, pearson correlation and multiple regression analysis. According to the results, the subjects's perception of nursing profession, major satisfaction, and nursing professionalism were 3.85 points, 3.95 points, and 3.85 points. In the sub-area of major satisfaction, recognition satisfaction was the highest and subject satisfaction was the lowest. In the sub-area of nursing professionalism, the nursing expertise area was the highest and the nursing independence area was the lowest. Also, among the general characteristics, there were differences in nursing recognition and major satisfaction according to the motivation for choosing a major. The nursing professionalism showed a significant positive correlation with nursing recognition and major satisfaction. Factors affecting nursing professionalism included major satisfaction, nursing recognition, with $64.7 \%$ explanation power. To establish positive nursing professionalism in nursing students, it is necessary to develop a variety of systematic educational programs to enhance their nursing recognition and major satisfaction.
\end{abstract}

Keywords: Major Satisfaction, Nursing Recognition, Nursing Professionalism, Nurse Students

\section{Introduction}

Nursing has grown steadily both internally and externally as a result of continuous focus on the status of the professional along with academic development, and in recent health management systems, nurses are recognized as a professional manpower that plays a pivotal role in patient healing[1].

Nursing college students who enter the department of nursing begin to form nursing professionalism while receiving theoretical and practical education professionally and are constantly changing and expanding[2]. Negative images of nurses can be created before the value of nursing and nursing professionalism are formed[3].

Nursing professionalism means how to view nursing and how to think about it. It is directly connected to the values of nursing, that is, the ideology, client, essence and purpose. It is an important concept that the value of nursing is recognized by the public as well as personal satisfaction through professional intuition[4]. Since individual nursing professional intuition is formed by professional education in college life, consideration should be given to professional skills and expertise, as well as values and attitudes toward nursing[5]. In the case of Korea, college students not only must adapt to the new environment and life in the education system centered on entrance examinations during the middle and high school days, but also invest a lot of time and effort to acquire the basic qualities and literacy necessary as professionals. Nursing college students experience the early development process and

Received: January 09, 2021; $1^{\text {st }}$ Review Result: February 23, 2021; $2^{\text {nd }}$ Review Result: April 10, 2021 Accepted: May 25, 2021 
transition to later development, which is an important turning point in one's life. The mental and psychological state formed at this time involves their future, and in particular, the nursing college students who will perform their duties as a professional have different emotions from those of ordinary college students. Nursing college students have a larger proportion of required major courses in theory and practice compared to students in other departments[6], and because of the mindset that decisionmaking as a medical practitioner, study on accurate and quick job performance[7]. Because of the mindset that the career direction is already determined here, there are many errors in satisfaction with the career and adaptation to the major[8]. However, compared to other majors, it is expected to have a firm belief in the future and enthusiasm for learning in the major field[9]. In order to be satisfied with a major like this, there may be negative feelings about the nursing major because there are various difficulties. However, rather than having negative feelings about the major, it is necessary to actively respond and strive to be satisfied. For a college nursing student, major satisfaction is a very important issue. In this way, one can immerse in the choosen major due to satisfaction, and can improve the quality of life through task solving and ability to reach the goals. Dissatisfaction with the major is an obstacle for college nursing students to form correct beliefs and attitudes for efficient job performance when they become nurses in the future[10].

Nursing job recognition is based on the concept of nurses' self-image about nursing job. When nursing students' positive perceptions about nurses are linked to clinical practice based on their major knowledge, correct perceptions about the nursing profession are established, and the formation of such positive and correct perceptions leads to nursing development with pride and pride as nurses. It becomes the power of nursing advancement[11][12]. On the contrary, if nursing students have confusion and negative views on their majors and jobs, they are not satisfied with their jobs or are unable to adapt in the clinical field[13][14].

Nursing college students need to understand the nature of nursing in the process of becoming a professional nurse and establish their own values. In clinical practice, nursing knowledge and skills as well as nursing professional intuition should be the basis when providing professional and holistic nursing to the subject. As nursing college students' value formation for nursing profession is a very important process, the degree of nursing professional intuition of nursing college students is checked, and the effect of major satisfaction and nurse image on nursing professional intuition is investigated to establish correct nursing professional values for nursing.

The specific research objectives are as follows.

1) Identify the general characteristics of the subjects, and investigate the degree of their nursing recognition, major satisfaction and nursing professionalism

2) Identify the differences in nursing recognition, major satisfaction and nursing professionalism according to the general characteristics of the subjects

3) Identify the correlation among nursing recognition, major satisfaction and nursing professionalism

4) Identify the factors that affect the nursing professionalism

\section{Method}

\subsection{Study Design}

This is a descriptive study aimed to understand the relationship between major satisfaction, nursing job perception, and nursing professional intuition of nursing students, and to investigate the effects of each other. 


\subsection{Subjects}

The subjects of this study were nursing students from $\mathrm{T}$ university located in $\mathrm{B}$ city who agreed to participate in the study after being informed of the purpose and procedure of the study. It was explained that the collected data will be used only for research purposes only, and that the respondents can withdraw from their participation any time. A total of 119 questionairees were distributed, but 112 cases were used for final analysis, excluding 7 cases with insuffient responses.

\subsection{Instruments}

\subsubsection{Major Satisfaction}

In other to measure the subjects' satisfaction towards their chosen major, this study used Lee's major satisfaction tool developed by Ha (2000). This tool consists of a total of 18 questions, consisting of four sub-areas: general satisfaction ( 6 questions), cognitive satisfaction ( 6 questions 0 , subject satisfaction (3 questions), and relationship satisfaction between professors and students (3 questions).

The measurement criterion uses a five-point Likert scale with one point as 'not at all' to five points as 'very much'. The higher the score, the higher the degree of satisfaction towards their major. As for the reliability of the tool, the Cronbach $\alpha$ value in Lee's study (2004) was 0.90, and the Cronbach $\alpha$ value in this study was .90 .

[Table 1] Item Composition and Reliability of Instrument

\begin{tabular}{cccc}
\hline Instrument & Question number & Number of Question & Reliability \\
\hline Major satisfaction & & 18 & .93 \\
\hline General satisfaction & $1,2,3,4,5,6$ & 6 & .89 \\
\hline Recognition satisfaction & $7,8,9,10,11,12$ & 6 & .85 \\
\hline Subject satisfaction & $13,14,15$ & 3 & .72 \\
\hline Relationship satisfaction & $16,17,18$ & 3 & .83 \\
\hline
\end{tabular}

\subsubsection{Nursing Recognition}

The tool created by Song (1993) to measure the image of a nurse for doctors, nurses, hospital staff, and the general public, tool modified and supplemented by Kim (2000)[15] were used. With a total of 40 questions, the standard of measurement is from 1 point "not at all" to 5 points "always" based on a Likert 5-point scale. The higher the score, the more positive the nursing job awareness is. For the two questions that had negative meanings for the nurse image, the conversion was reversed.

The reliability of the tool was Cronbach $\alpha .95$ in Kim's study(2000) and Cronbach $\alpha .93$ in this study.

\subsubsection{Nursing professionalism}

To measure nursing professionalism, the tool developed by Yeun et al. (2005) and modified and supplemented by Lee (2011)[16] was used. This tool consists of a total of 26 questions and of sub-areas namely 'professional self-concept'(9 question), 'social recognition'(question), 'professionality in nursing'(4 question) 'role of nursing community'(3 question) and 'independent nursing'(2 question) The standard of measurement is from 'Not at all' 1 point to 'Very so' 5 points. The higher the score, the higher the nursing professional intuition.

In Lee's study (2011), the Cronbach $\alpha$ was .91 while .87 in this study. 
[Table 2] Item Composition and Reliability of Instrument

\begin{tabular}{cccc}
\hline Instrument & Question Number & Number of Question & Reliability \\
\hline Nursing professionalism & & 18 & .93 \\
\hline Self concept of the profession & $1,2,3,4,5,6,7,8,9$ & 9 & .82 \\
\hline Social recognition & $10,11,12,13,14,15,17,18$ & .82 \\
\hline Professionality of nursing & $19,20,21,22$ & 8 & .71 \\
\hline Role of nursing community & $23,24,25$ & 3 & .72 \\
\hline Indipendence of nursing & 16,26 & 2 & .65 \\
\hline
\end{tabular}

\subsection{Data Collection and Analysis}

\subsubsection{Data Collection}

The data collection period took place from March 25, 2020 to April 01, 2020 with the help of the university department. The purpose of the study was directly explained to the study subjects, and the personal information entered in the questionnaire was guaranteed to be confidential, and the results of the questionnaire were not used for purposes other than the study. The decision to participate in the study was voluntary, and the subjects who indicated their intention to participate in the study were asked to fill out a written consent form and questionnaire

\subsubsection{Data Analysis}

The collected data were analyzed using IBM SPSS Statistics Version 25. The general characteristics of the study subjects were analyzed by frequency and percentage while the degree of major satisfaction and nurse image and the degree of nursing professional intuition were analyzed by means and standard deviation. In order to find out the correlation between nursing professional intuition, Pearson's Correlation Analysis was performed, and the effect of nurse image and major satisfaction on nursing professional intuition was analyzed by multiple regression.

\section{Results}

\subsection{General Characteristics}

The general characteristics of the study subjects are as shown in [Table 1]. The total number of subjects of the study was 112, with 39 (34.8\%) people under 20 years of age, 23 (20.5\%) people over 24 years old, $21(18.8 \%)$ people aged $23,19(17.0 \%)$ aged 21 , and $10(8.9 \%)$ people aged 22 . In terms of grade, '4th grade' was the most common with 48 (42.9\%), '1st grade' $23(20.5 \%)$, '3rd grade' 22 $(19.6 \%)$,and '2nd grade' $19(17.0 \%)$. In terms of gender, 88 (78.6\%) were'female' and 24 (21.4\%) were'male'. When asked about the motives for choosing nursing, $60(53.6 \%)$ respondents answered 'hope for themselves', 32 (28.6\%) respondents with 'high employment rate', 15 (13.4\%) answered 'recommendation to others'. 5(4.5\%) with 'according to grade'. Among the immediate family members, $92(82.1 \%)$ answered that there were no nurses, and $20(17.9 \%)$ answered that there were nurses in the family. 
[Table 3] General Characteristics ( $\mathrm{N}=112$ )

\begin{tabular}{ccc}
\hline Charicteristics & Category & $\mathrm{n}(\%)$ \\
\hline \multirow{2}{*}{ Sex } & Male & $24(21.4)$ \\
\cline { 2 - 3 } & Demale & $88(78.6)$ \\
\cline { 2 - 3 } & Under 20 & $39(34.8)$ \\
\cline { 2 - 3 } & $21-23$ & $50(44.7)$ \\
\cline { 2 - 3 } Grade & Over 24 & $23(20.5)$ \\
\cline { 2 - 3 } & 1 grade & $23(20.5)$ \\
\cline { 2 - 3 } & 2 grade & $19(17.0)$ \\
\hline \multirow{3}{*}{ Motivation for major } & 3 grade & $22(19.6)$ \\
\cline { 2 - 3 } selection & 4 grade & $48(42.9)$ \\
\cline { 2 - 3 } & High employment rate & $60(53.6)$ \\
\cline { 2 - 3 } & Surrounding advice & $32(28.6)$ \\
\hline \multirow{2}{*}{ Have a nurse in the family } & According to grade & $15(13.4)$ \\
\cline { 2 - 3 } & Yes & $5(4.5)$ \\
\hline
\end{tabular}

\subsection{Degree of the Nursing Recognition, Major Satisfaction and Nursing Professionalism}

[Table 4] shows the degree of nursing job perception, major satisfaction, and nursing professionalism of the study subjects. The degree of nursing job recognition was 3.85 (.40), major satisfaction was 3.95 (.51), and nursing professional intuition was 3.85 (.39). In the sub-area of major satisfaction, recognition satisfaction was the highest with 4.27 points and subject satisfaction was the lowest with 3.59points. In the sub-area of nursing professionalism, the nursing expertise area was the highest with 4.14points and the nursing independence area was the lowest with 2.58points.

[Table 4] Mean Score of the Nursing Recognition, Major Satisfaction and Nursing Professionalism

\begin{tabular}{cccc}
\hline Variables & Mean \pm sd & Minimum value & Maximum value \\
\hline Nursing recognition & $3.85 \pm .40$ & 1.00 & 5.00 \\
\hline Major satisfaction & $3.95 \pm .51$ & 1.00 & 5.00 \\
\hline General satisfaction & $3.94 \pm .63$ & 2.17 & 5.00 \\
\hline Recognition satisfaction & $4.27 \pm .57$ & 2.67 & 5.00 \\
\hline Curriculum satisfaction & $3.59 \pm .74$ & 1.33 & 5.00 \\
\hline Relationship satisfaction & $3.63 \pm .80$ & 1.00 & 5.00 \\
\hline Nursing professionalism & $3.85 \pm .39$ & 1.00 & 5.00 \\
\hline Self concept of the profession & $3.93 \pm .45$ & 2.44 & 5.00 \\
\hline Social recognition & $3.67 \pm .57$ & 2.13 & 5.00 \\
\hline Professionality of nursing & $4.14 \pm .50$ & 2.75 & 5.00 \\
\hline Role of nursing community & $3.97 \pm .56$ & 2.00 & 5.00 \\
\hline Independence of nursing & $2.58 \pm .95$ & 1.00 & 5.00 \\
\hline
\end{tabular}




\subsection{Diference in the Nursing Recognition, Major Satisfaction and Nursing Professionalism according to General Characteristics}

[Table5] shows the results of analyzing differences in nursing recognition, major satisfaction and nursing professionalism according to general characteristics. Threr was no significant diference in gender $(\mathrm{F}=1.586, \mathrm{p}=.116)$ age $(\mathrm{F}=1.868, \mathrm{p}=.159)$, $\operatorname{grade}(\mathrm{F}=1.342, \mathrm{p}=.265)$ and have a nurse in family $(\mathrm{F}=-.835, \mathrm{p}=.406)$ in the nursing recognition, but there was a significant diference in major selection motivation $(\mathrm{F}=2.736, \mathrm{p}=.047)$. The group who answered high wages was more aware of the nursing job than group who applied based on their grade. In the case of major satisfaction, there was a significant diference only in the major selection motivation $(\mathrm{F}=5.987, \mathrm{p}=.001)$. According to the results of post-hoc analysis, the group who answered that they applied because they wanted showed higer major satisfaction score than the group who answered that they applied because of high wages. In nursing professionalism, there was no significant diference according to all general characteristics.

[Table 5] Differences in the Nursing Recognition, Major Satisfcation and Nusing Professionalism according General Characteristics

\begin{tabular}{|c|c|c|c|c|c|c|c|}
\hline \multirow{2}{*}{$\begin{array}{l}\text { Characteri } \\
\text { stics }\end{array}$} & \multirow{2}{*}{ Category } & \multicolumn{2}{|c|}{ Nursing recognition } & \multicolumn{2}{|c|}{ Major satisfaction } & \multicolumn{2}{|c|}{ Nursing professionalism } \\
\hline & & $\mathrm{M} \pm \mathrm{SD}$ & t or $F(p)$ & $\mathrm{M} \pm \mathrm{SD}$ & t or $F(p)$ & $\mathrm{M} \pm \mathrm{SD}$ & \\
\hline \multirow{2}{*}{ Sex } & Male & $3.96 \pm .46$ & \multirow{2}{*}{$\begin{array}{l}1.586 \\
(.116)\end{array}$} & $4.09 \pm .45$ & \multirow{2}{*}{$\begin{array}{l}1.592 \\
(.114)\end{array}$} & $3.83 \pm .47$ & \multirow{2}{*}{$\begin{array}{c}.673 \\
(.502\}\end{array}$} \\
\hline & Female & $3.82 \pm .38$ & & $3.90 \pm .51$ & & $3.77 \pm .35$ & \\
\hline \multirow{3}{*}{ Age } & Under 20 & $3.77 \pm .38$ & \multirow{3}{*}{$\begin{array}{l}1.868 \\
(.159)\end{array}$} & $3.88 \pm .52$ & \multirow{3}{*}{$\begin{array}{c}.457 \\
(.653)\end{array}$} & $3.68 \pm .37$ & \multirow{3}{*}{$\begin{array}{l}2.460 \\
(.090)\end{array}$} \\
\hline & $21-23$ & $3.93 \pm .42$ & & $3.98 \pm .49$ & & $3.86 \pm .36$ & \\
\hline & Over 24 & $3.81 \pm .37$ & & $3.96 \pm .52$ & & $3.78 \pm .40$ & \\
\hline \multirow{4}{*}{ Grade } & 1grade & $3.70 \pm .39$ & \multirow{4}{*}{$\begin{array}{l}1.342 \\
(.265)\end{array}$} & $3.90 \pm .57$ & \multirow{4}{*}{$\begin{array}{l}.787 \\
(.504)\end{array}$} & $3.65 \pm .39$ & \multirow{4}{*}{$\begin{array}{l}2.025 \\
(.504)\end{array}$} \\
\hline & 2grade & $3.86 \pm .41$ & & $3.80 \pm .52$ & & $3.69 \pm .36$ & \\
\hline & 3grade & $3.90 \pm .41$ & & $4.03 \pm .53$ & & $3.83 \pm .39$ & \\
\hline & 4grade & $3.85 \pm .39$ & & $3.98 \pm .46$ & & $3.86 \pm .36$ & \\
\hline \multirow{4}{*}{$\begin{array}{l}\text { Motivatio } \\
\mathrm{n} \text { for } \\
\text { major } \\
\text { selection }\end{array}$} & Wanted & $3.94 \pm .38$ & \multirow{4}{*}{$\begin{array}{l}2.736 \\
(.047)\end{array}$} & $4.12 \pm .46$ & \multirow{4}{*}{$\begin{array}{l}5.987 \\
(.001) \\
a>b\end{array}$} & $3.83 \pm .38$ & \multirow{4}{*}{$\begin{array}{l}1.055 \\
(.371)\end{array}$} \\
\hline & $\begin{array}{l}\text { High employ } \\
\text {-yment rate }\end{array}$ & $3.72 \pm .39$ & & $3.73 \pm .43$ & & $3.71 \pm .35$ & \\
\hline & $\begin{array}{c}\text { Surrounding } \\
\text { advice }\end{array}$ & $3.85 \pm .46$ & & $3.82 \pm .61$ & & $3.78 \pm .47$ & \\
\hline & $\begin{array}{l}\text { According to } \\
\text { grade }\end{array}$ & $3.60 \pm .28$ & & $3.58 \pm .41$ & & $3.63 \pm .17$ & \\
\hline \multirow{2}{*}{$\begin{array}{l}\text { Have a nurse } \\
\text { in the family }\end{array}$} & Yes & $3.78 \pm .40$ & \multirow{2}{*}{$\begin{array}{l}-.835 \\
(.406)\end{array}$} & $3.85 \pm .59$ & \multirow{2}{*}{$\begin{array}{l}-.858 \\
(.393)\end{array}$} & $3.78 \pm .40$ & \multirow{2}{*}{$\begin{array}{r}-1.060 \\
(.291)\end{array}$} \\
\hline & No & $3.86 \pm .40$ & & $3.96 \pm .49$ & & $3.86 \pm .40$ & \\
\hline
\end{tabular}

\subsection{Correlation among Nursing Job Perception, Major Satisfaction, Nursing Professionalism}

[Table 6] shows the results of the correlation analysis between research subjects' perception of nursing job, major satisfaction, and level of nursing professional intuition. Nursing job recognition was found to have a positive correlation with major satisfaction $(\mathrm{r}=.648, \mathrm{p}<.001)$, and with nursing professionalism 
$(\mathrm{r}=.786, \mathrm{p}<.001)$. The relationship between major satisfaction and nursing professionalism had a positive correlation $(\mathrm{r}=.652, \mathrm{p}<.001)$.

[Table 6] Correlation among Nursing Recognition, Major Satisfaction, Nursing Professionalism

\begin{tabular}{cccc}
\hline Variables & Nursing recognition & Major satisfaction & Nursing professionalism \\
\hline Nursing recognition & 1 & & \\
\hline Major satisfaction & $.648(<.001)$ & 1 & 1 \\
\hline Nursing professionalism & $.786(<.001)$ & $.652(<.001)$ & \multirow{2}{*}{} \\
\hline
\end{tabular}

\subsection{Effect of Major Satisfaction and Nursing Perception on Nursing Professionalism}

[Table 7] shows the results of regression analysis to understand the effect of major satisfaction and nursing job perception on nursing professionalism. The regression model was statistically significant $(\mathrm{F}=102.654, \mathrm{p}<.001)$ and showed $64.7 \%$ explanatory power.

Nursing job recognition $(\beta=.627, p<.001)$ and major satisfaction $(\beta=.246, p=.001)$ were found to have a statistically significant effect on nursing professional intuition.

The higher the nursing profession awareness was, the higher the nursing professional intuition was. The higher the degree of satisfaction with the major, the higher the nursing professional intuition. In addition, it was found that nursing job recognition had a greater influence than major satisfaction.

[Table 7] Effect of Major Satisfaction and Nursing Perception on Nursing Professionalism

\begin{tabular}{cccccccc}
\hline & Variable & & $\mathrm{B}$ & $\mathrm{SE}$ & $\beta$ & $\mathrm{t}$ & $\mathrm{p}$ \\
\hline \multirow{2}{*}{$\begin{array}{c}\text { Nursing } \\
\text { professionalism }\end{array}$} & \multicolumn{2}{c}{ Constant } & .742 & .218 & & 3.404 & $<.001$ \\
\cline { 2 - 7 } & $\begin{array}{c}\text { Nursing } \\
\text { recognition }\end{array}$ & .611 & .072 & .627 & 8.461 & $<.001$ \\
\cline { 2 - 7 } & $\begin{array}{c}\text { Major } \\
\text { satisfaction }\end{array}$ & .191 & .057 & .246 & 3.326 & .001 \\
\hline \multicolumn{7}{c}{$\mathrm{R} 2=6.53$, Adjusted R2 $=.647 \mathrm{~F}=102.654 \mathrm{p}<.001$} \\
\hline
\end{tabular}

\section{Discussion}

The following discussion focus on the results of this study.

Nursing students' perception of nursing job was 3.85 out of 5 points, higher than 3.75 points in Lee's study[16] and lower than 3.92 points in Jo's study[17]. It was found to be consistent with 3.85points in the study result of Seong et al.[18]

In this study, the major satisfaction was 3.95 points, which was higher than 3.88 points of Jang's study which used the same tools among nursing students[19] and lower than 3.96 points in Jo's study[17]. This may have been different depending on the subject. In the case of recent high school students entering Korean universities, they enter the university without considering their personal values. They choose a major based on their grades or expectations without sufficient understanding of the course or their actual preferences.. It was confirmed that th are many cases leading to maladjustment, dissatisfaction, and mental conflict with the majors[19]. It is necessary to provide a variety of major satisfaction improvement programs so that nursing students who have entered college can increase their major satisfaction. 
The average score for nursing professional intuition was 3.85 points, which was similar to the study result of Seong et al.[18] with 3.83 points. Students perceive the nursing profession as a nurse most importantly as a part of a practical role or a professional part. However, as shown in the results of Ju and Shin[20], if a nurse is considered to be a person who plays an auxiliary role in helping the doctor's work, it is thought that it would have been low in terms of nursing identity. This is because there may be areas where students are not aware of the areas where the independent area of nurses is currently expanding, so it is thought that in the future, education for students to improve their awareness of independent nursing areas is expected

In this study, the results of the correlation analysis between nurse image, major satisfaction and nursing professional intuition were analyzed. It was confirmed that the nurse image and major satisfaction had a positive relationship with the nursing professional intuition of nursing students. The higher the nurse image and major satisfaction, the higher the nursing professional intuition. There was also some agreement with the study results of which showed a significant positive correlation between the nurse image and nursing professionalism[17].

The subjects' perception of nursing job and major satisfaction were found to be factors that influence nursing professional intuition. This was the influencing factor of nursing professional intuition, in the order of nurse image, major satisfaction, and personality, which was consistent with Jo's research results and with an explanatory power of $64.7 \%$. People with positive self-image tend to think of themselves as competent, and those with negative self-image tend to think of themselves as incompetent . In the future, a positive self-image can be a source for setting the direction of life for college nursing students who have to deal with diverse and large numbers of subjects in complex clinical situations and prepare for the path of nurses who require extensive knowledge and trained professional skills.

This would have helped a lot to positively establish nursing professionalism with pride and pride as a college nursing student. However, in order to improve the negative social image or nursing professional intuition, which is still recognized, institutional preparation such as improvement of the nursing work environment and the treatment of nurses is considered necessary. Considering that the nursing professional intuition is a conscious view of the nursing world, the nurse's image of correct values and expertise is directly connected to the nursing professional intuition. The perception towards nurses will become more solid.

In addition, it is necessary to establish a professional identity through the nursing curriculum and to use the curriculum and comparison programs to improve major satisfaction[19]. In particular, it is considered that the curriculum needs to be improved reflecting the changed clinical field required as a prospective nurse.

\section{Conclusion}

The purpose of this study is to understand the degree of nursing job recognition, major satisfaction and nursing professional intuition among college nursing students, and the relationship between them.

The data was collected through a structured questionnaire from March 25 to April 01, 2020, targeting 112 students in the 1st, 2nd, 3rd, and 4th grades of T University college located in B city, and was analyzed using SPSS statistical program ( ver.25) to obtain the following results.

The subjects' perception of nursing profession, major satisfaction, and nursing professional intuition were 3.85points, 3.95points, and 3.85points, respectively. In the sub-area of major satisfaction, recognition satisfaction was the highest and subject satisfaction was the lowest. In the sub-area of nursing professionalism, the nursing expertise area was the highest and the nursing independence area was the lowest.

As a result of analyzing differences in nursing recognition, major satisfaction and nursing professionalism according to general characteristics, significant differences were found in nursing 
recognition and major satisfaction in the case of major selection motivation. Students who applied because they wanted had higher recognition score of nursing than students who applied according to their grades. Also, students who applied because they wanted had higher The subjects' perception of nursing profession, major satisfaction, and nursing professional intuition were 3.85 (.40) points, 3.95 (.51) points, and 3.85 (.39) points, respectively. had higher satisfaction score of major than that of the group who applied because of their high wages.

Nursing job perception was positively correlated with major satisfaction and nursing professional intuition, and major satisfaction to nursing professional intuition showed a positive correlation, and there was a statistically significant positive correlation between each variable.

Research subjects' perception of nursing profession and major satisfaction were found to have a statistically significant effect on nursing professional intuition.

The higher the nursing profession perception was, the higher the nursing professional intuition, and the higher the major satisfaction was, the higher the nursing professional intuition.

Furthermore, it was found that nursing job recognition had a greater influence than major satisfaction.

\section{References}

[1] Y. J. Yang, S. A. Park, The Effects of Nursing Image, Major Satisfaction, and Nursing Professionalism on Career Preparation Behavior of Nursing Students: For Nursing Students in Chungcheong and Gangwon Areas, Culture and Convergence, (2020), Vol.42, No.10, pp.903-930.

[2] M J. Schank, D. Weis, Service and education share responsibility for nurses' value development, Journal for Nurses in Staff Development, (2001), Vol.17, Vol.5, pp.226-231, DOI: 10.1097/00124645-200109000-00002

[3] H. J. Park, Correlations Among Nursing Professionalism, Critical Thinking Disposition and Self-leadership in Nursing Students, The Journal of Korean Academic Society of Nursing Education, (2015), Vol.21, No.2, pp.227-236, DOI: https://doi.org/10.5977/jkasne.2015.21.2.227

[4] D. Adams, B. K. Miller, Professionalism in nursing behaviors of nurse practitioners, Journal of Professional Nursing, (2001), Vol.17, No.4, pp.203-210, DOI: 10.1053/jpnu.2001.25913

[5] E. A. Herdman, Nursing in a post emotional society, Nursing Philosophy, (2004), Vol.5, No.2, pp.95-103, DOI:10.1111/j.1466-769X.2004.00169.x

[6] H. J. Shin, H. J. Park, Effect of nursing college student's major flow experience on Career Decision-Making SelfEfficacy and career attitude maturity, The Journal of Learner-Centered Curriculum and Instruction, (2017), Vol.17, No.22, pp.643 -664, DOI : 10.22251/jlcci.2017.17.22.643

[7] Y. K. Kwag, Effect of Self-Esteem, Ego-Resilience, Social Support on Nursing student's Adjustment to College, Journal of Korea Academia-Industrial cooperation Society, (2013), Vol.14, No.5, pp.2178- 2186, DOI : 10.5762/KAIS.2013.14.5.2178

[8] I. S. Park, Y. J. Han, A Study on the Difference in Career Attitude Maturity, Career Identity, Stress Management, and Satisfaction for Major Classes of Nursing Students According to Demographic Characteristics, Journal of Employment and Career, (2017), Vol.7, No.1, pp.145-167, DOI : 10.35273/jec.2017.7.1.007

[9] J. S. Yoo, S. Y Choi, The Effects of Major Commitment Level by Department Climate among Students at the Department of Dental Hygiene, Journal of Dental Hygiene Science, (2011), Vol.11, No.2, pp.99-105.

[10] D. Barron, E. West, R. Reeves, Tied to the job : Affective and relational components of nurse retention, Journal of Health Services Research \& Poicy, (2007), Vol.12, pp.46-51, https://doi.org/10.1258/135581907780318419

[11] E. K. Lee, E. J. Ji, Factors Influencing Nursing Professionalism in Nursing Students: Clinical Learning Environment and Attitude toward Nurse-Physician Collaboration, Journal of Korean Academy of Fundamentals of Nursing, (2016), Vol.23, No.2, pp.126-135, http://dx.doi.org/10.7739/jkafn.2016.23.2.126 
[12] K. M. Lim, E. J. Jo, Influence of Satisfaction with Clinical practice and Image of nurses on Nursing professionalism of Nursing students, Journal of Korea Academia-Industrial Cooperation Society, (2016), Vol.17, No.4, pp.556-566, http://dx.doi.org/10.5762/KAIS.2016.17.4.556

[13] J. H. Park, Effects of Documentary Education on Study Crafting and Nursing Recognition in Nursing Students, Journal of Korea Academia-Industrial cooperation Society, (2019), Vol.20, No.8 pp.264-270, https://doi.org/10.5762/KAIS.2019.20.8.264

[14] D. J. Lee, Relationships among satisfaction in major, gender identity, and gender stereotypes of male nursing students, Yonsei University, Master's thesis, (2004)

[15] H. J. Kim, A Study of the Image of the Nurse, Chonbuk National University, Master' s thesis, (2000)

[16] S. R. Lee, Nurse Image, Satisfaction of Major, effect on Nursing Professionalism of Male Students in Nursing, Ajou University, Master's thesis, (2011)

[17 ] H. E. Jo, Y. H. Ahn, S. M. Ryu, J. Y. Lim, H. G. Kim, The Effect of the Image of Nurses and the Major Satisfaction on the Nursing Professionalism among Nursing students in University, Journal of the Korean Applied Science and Technology, (2019), Vol.36, No.3, pp.1008-1017, https://doi.org/10.12925/jkocs.2019.36.3.1008

[18 ] J. A. Seong, E. Y. Yeom, G. S. Do, Image of Nurses and Nursing Professional Values Perceived by Nursing Students, Journal of the Korean Content Society, (2004), Vol.14, No.11, pp.798-809, https://doi.org/10.5392/JKCA.2014.14.11.798

[19] H. J. Jang, Effects of Image of Nurse, Clinical Performance, and Major Satisfaction of Nursing Students on Nursing Professionalism, Journal of the Korean Applied Science and Technology, (2020), Vol.37, No.3, pp.635-648, https://doi.org/10.12925/jkocs.2020.37.3.635

[20] M. K. Ju, G. Y. Shin, Nursing Image and Professionalism Perceived by Male and Female Nursing Students in College, The Journal of Korean Academic Society of Nursing Education, (2012), Vol.18, No.3, pp.510-521, DOI : 10.5977/jkasne.2012.18.3.510 